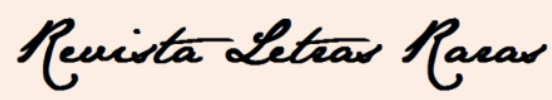

ISSN: 2317-2347 - Vol. 5, Ano 5, № 2 - 2016

\title{
A ambientação e a construção da história: tradução comentada do conto 'The First Day', ambientado em João Pessoa (PB)
}

\author{
Edilza Detmering * \\ Daniel Antonio de Sousa Alves**
}

\begin{abstract}
Resumo: Este trabalho tem como objetivo principal apresentar uma tradução comentada do conto The First Day, de Edward P. Jones, para o português brasileiro, introduzindo a narrativa no cenário Pessoense contemporâneo. Ao apresentar uma tradução juntamente com a discussão sobre o projeto tradutório e as escolhas de tradução feitas, este trabalho busca dar visibilidade à tradução, ao mesmo tempo em que reflete sobre a importância do cenário na construção da história e sobre as possibilidades em lidar com elementos da cultura afro-americana presentes no conto em uma situação de tradução. A proposta deste trabalho (em traduzir um conto e problematizar a tradução) se baseia nas propostas teóricas de Berman (1995) - sobre como projetos de tradução se articulam às crenças, posições e limitações do tradutor frente a um texto - , de Venuti (1995) - no embasamento sobre apropriação textual e visibilidade da tradução - e de Baker (2014) - ao refletir sobre o papel da tradução reduzir a marginalidade cultural de grupos sociais (no caso do conto aqui trabalhado, de grupos de cultura afro-americana). Sem a pretensão de encerrar o debate sobre as escolhas tradutórias, este artigo possibilita: aventar questionamentos visando uma maior conscientização sobre o papel social da tradução; refletir sobre o/a tradutor/a enquanto autor/a e agente social; e, suscitar a escrita de outros projetos tradutórios que abordem questões étnicoraciais.
\end{abstract}

Palavras-chave: Estudos da Tradução. Visibilidade da tradução. Cultura afro-americana.

\section{The setting and the construction of history: commented translition of the short story 'The First Day', set in João Pessoa (PB)}

\begin{abstract}
This paper aims at presenting a commented translation of the short story 'The First Day' (by Edward P. Jones), originally written in American English, into Brazilian Portuguese, setting it in a contemporary João Pessoa. By presenting a translation and the translation project behind it, and by discussing the translation choices made, this article attempts to give visibility to the translation itself, while reflecting on the importance of the setting for construing the narrative and on the possibilities of dealing with elements of African-American culture that appear in the story in a translation situation. The purpose of this article (to translate a short story and discuss the translation) is based on Berman (1995) on articulating translation projects with the translator's beliefs and the constraints posed to the text - , on Venuti (1995) - on textual appropriation and translation visibility —, on Baker (2014) — on the role translation plays in promoting aspects of the lived experience of marginalized groups. Not intended to wind up the debate on translational choices, this article fosters a debate on the social roles of translation;
\end{abstract}

\footnotetext{
* Especialização em Linguística pela Universidade Federal da Paraíba, Brasil (2010). Técnico de Tecnologia da Informação da Universidade Federal da Paraíba, Brasil. Contato: detmering@ sti.ufpb.br

** Doutor em Estudos da Tradução pela Universidade Federal de Santa Catarina (2014) e Mestre em Estudos Linguísticos pela Universidade Federal de Minas Gerais (2006), é Professor Adjunto da Universidade Federal da Paraíba, atuando em ensino e pesquisa relacionados a Tradução e Conflito; Linguística de Corpus, Tecnologia da informação, Linguística Sistêmico-Funcional; e em atividades de extensão na formação de tradutores(as).Especialização em Linguística pela Universidade Federal da Paraíba, Brasil (2010). Técnico de Tecnologia da Informação da Universidade Federal da Paraíba, Brasil. Contato: daniel@cchla.ufpb.br
} 


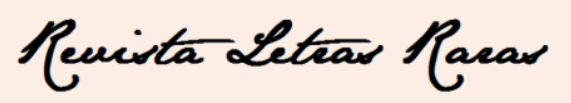

ISSN: 2317-2347 - Vol. 5, Ano 5, № 2 - 2016

on the roles of the translator as a social agent; and encourages other translation projects that address ethnic and racial issues.

Keywords: Translation Studies. Translation visibility. African-American culture.

\section{Introdução}

Este artigo objetiva apresentar uma tradução comentada do conto The First Day, do escritor Edward P. Jones ${ }^{1}$, para o português brasileiro contemporâneo. Originalmente escrito em inglês, o conto é aqui traduzido para o português brasileiro contemporâneo - partindo da proposta, a ser mais bem explicitada na seção 2 deste trabalho, de ambientá-lo no cenário nordestino brasileiro - e as escolhas tradutórias são discutidas, com vistas a suscitar uma reflexão sobre o local de fala da tradutora ${ }^{2}$ em relação ao outro cultural, promovendo, ao mesmo tempo, reflexões sobre o papel da tradução em reduzir ou acentuar a marginalidade cultural de grupos sociais, como propõe Baker (2014), e sobre a visibilidade da tradutora, ao apresentar uma racionalização sobre o processo de tradução desenvolvido, como propõe Venuti (1995).

Partindo da proposta de Meyer (2002), em entender ambientação como o contexto em que a ação de uma história acontece — e contemplando os âmbitos temporal, geográfico e sociocultural da palavra contexto - este trabalho pretende promover uma reflexão sobre a importância da ambientação para a construção de uma narrativa. Além da discussão ora proposta, este trabalho também busca promover, como apontado no parágrafo anterior, a visibilidade da tradução, apoiando-se na proposta de Venuti (1995, p. 311), de "apresentar fundamentos sofisticados para (...) práticas [de tradução] em prefácios, ensaios, palestras, entrevistas"3, ou como acontece aqui, em um estudo de caso que destaca a racionalização do projeto de tradução e das decisões tradutórias. Outrossim, esta discussão permite verificar como os dois textos (o conto em inglês e sua tradução para o português) constroem as realidades nas quais suas narrativas se inserem, especialmente em termos dos elementos de ambientação e dos

\footnotetext{
${ }^{1}$ Professor do Departamento de Língua Inglesa do Columbian College of Arts \& Sciences, onde ensina a escrever ficções, vencedor do Prêmio Pulitzer pela obra The Known World. A ele, os nossos sinceros agradecimentos por consentir (em contato via e-mail) a publicação do texto traduzido e desta discussão em uma publicação acadêmica, sem fins lucrativos.

${ }^{2}$ Apesar de este artigo ser escrito em parceria, a ocorrência do feminino singular ao longo do texto serve para marcar a visibilidade da tradutora.

${ }^{3}$ Tradução de "presenting sophisticated rationales for (...) [translation] practices in prefaces, essays, lectures, interviews". A menos que especificado de outra forma, todas as traduções de citações colocadas neste artigo são nossas.
} 


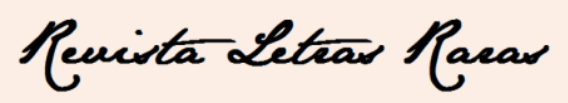

ISSN: 2317-2347 - Vol. 5, Ano 5, № 2 - 2016

impactos que esses elementos têm sobre tais narrativas. Segundo Meyer (2002), "as características temporais, geográficas e físicas de um ambiente podem ser relevantes para o propósito geral de uma narrativa bem como o ambiente social em que se desenvolvem as personagens." ${ }^{4}$ Ainda, de acordo com o autor, são esses elementos constitutivos de narrativas - tempo, espaço, ambiente social — que alicerçam os universos em que as personagens agem e é a partir deles que os comportamentos, sentimentos e ações das personagens podem ser compreendidos, sendo lícito supor, para fins desta discussão, que a depender do cenário de cada texto, os efeitos na comunidade receptora podem ser distintos.

Para desenvolver a proposta delineada nesta introdução, este artigo se organiza em 4 seções além desta Introdução, a saber: a seção 2, a seguir, Desdobramentos $e$ discussões, apresenta quatro subdivisões e detalha o projeto tradutório e as reflexões acerca das escolhas tradutórias, aprofundando a análise de algumas passagens do texto; a seção 3, Conto em inglês e respectiva tradução para o português brasileiro, apresenta o texto fonte e o texto alvo, lado a lado, permitindo que se tenha uma visão geral de ambos; a seção 4, Considerações da tradutora apresenta tanto reflexões sobre o processo tradutório quanto reflexões pessoais da tradutora em torno de seu envolvimento no projeto aqui explicitado.

\section{Desdobramentos e discussões sobre o texto fonte e o projeto tradutório}

Publicado no livro Lost in the city, escrito por Edward P. Jones, o conto The First Day ${ }^{5}$ apresenta a narrativa do primeiro dia de uma garota na escola. Narrado em primeira pessoa pela narradora, que relembra a experiência de ser levada pela mãe à escola, o processo de matrícula, as dificuldades da mãe em matriculá-la na escola Seaton Elementary School (uma escola mais afastada de onde residem) por não saber ler nem escrever e se ver em uma situação em que precisa de ajuda para preencher os formulários de matrícula.

\footnotetext{
${ }^{4}$ Tradução de "Time, location, and the physical features of a setting can all be relevant to the overall purpose of a story. So too is the social environment in which the characters are developed."

${ }^{5} \mathrm{Em}$ https://www.youtube.com/watch?v=CkS05i_HTJg (Acesso em: 30 ago. 2016), é possível ter acesso a uma leitura do conto, pelo autor, durante o evento Connections Literary Series, em College of Southern Maryland.
} 


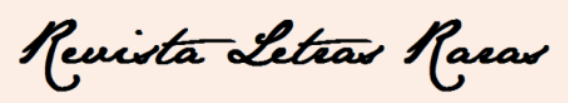

ISSN: 2317-2347 - Vol. 5, Ano 5, № 2 - 2016

Lembrando todo o contexto da experiência, a narradora apresenta os detalhes da ambientação - incluindo o perfume, a caminhada pelas ruas da cidade, a descrição das personagens e dos espaços por onde elas circulam, para nomear alguns - e suas impressões, concluindo sua narração com o momento em que é deixada aos cuidados da professora, enquanto observa sua mãe ir embora, destacando que ainda consegue escutar os passos da mãe, que ecoam no corredor.

Os detalhes da ambientação, apontados no parágrafo anterior, tanto auxiliam na compreensão dos conflitos existentes no conto, quanto representam um desafio para qualquer tradutor que se proponha a promover mudanças nessa ambientação, - a exemplo do projeto abordado no presente trabalho - por se tratar de um enredo repleto de marcadores culturais específicos que podem restringir o leque de escolhas tradutórias possíveis. No entanto, e até por esta razão, esse desafio instigante serviu de motivação para que o conto The First Day fosse trabalhado e trouxesse questionamentos e reflexões sobre a importância da ambientação para a história.

Os recursos utilizados para a ambientação do conto marcam o contexto social americano, o qual apresenta distinções em relação ao contexto brasileiro — distinções essas inerentes ao próprio ambiente cultural e suas peculiaridades. Uma proposta de tradução que defenda uma ambientação local é possível de ser implementada desde que, como destaca Berman (1995), os termos dessa tradução sejam previamente estabelecidos e a tradução se baseie em um projeto tradutório que articule as crenças do tradutor e as restrições impostas pelo texto. Ainda segundo o autor, a tradução deve revelar o posicionamento do tradutor acerca de como realizar uma tradução e como escolher dentre as várias maneiras de se traduzir.

Quanto ao meu posicionamento em relação ao conto, posso afirmar que, em primeiro lugar, enquanto antropóloga, admiro a proposta e a escrita de Edward P. Jones, pela clareza com que ele expõe as subjetividades das suas personagens e pelas discussões que seus textos propiciam. Em segundo lugar, no que concerne ao meu trabalho como tradutora, compreendo que, enquanto agente social, tenho um papel importante a desempenhar no desenvolvimento da consciência político-social, e este conto permite que esse papel seja exercido e repensado. 


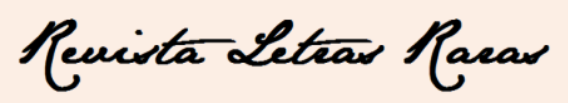

ISSN: 2317-2347 - Vol. 5, Ano 5, № 2 - 2016

Acerca do meu projeto tradutório, optei por ambientar o conto na cidade de João Pessoa, capital da Paraíba, estado da Região Nordeste do Brasil, para suscitar a reflexão e problematizar, principalmente as características do cenário em si. Mas optei também em fazê-lo, para pensar os elementos de ambientação que apontam para os elementos da cultura afro-americana (no texto fonte) e os elementos que apontam para a cultura afrobrasileira (no texto alvo), incluindo questões sobre condições socioculturais das personagens.

No texto alvo, o local em que o enredo se desenrola, efetivamente, é o centro da cidade de João Pessoa. Em um cenário nordestino, mais especificamente Pessoense, é feito o relato de um dia na vida das protagonistas - pessoas simples, de condição social marginalizada que buscam, por meio da educação, um meio de romper essa condição de marginalização —, sendo apresentados elementos culturais marcantes que se destacam no enredo e uma tentativa de inserção de moradores da periferia da cidade em espaços ocupados pela classe média.

Em termos de ambientação temporal, a tradução busca construir uma época não muito distante daquela construída no texto fonte. Ou seja, foram escolhidas referências a produtos conhecidos e utilizados no Brasil na mesma época ${ }^{6}$ em que, por exemplo, o perfume, os alimentos, o tipo de roupa e os ornamentos descritos no texto fonte circulavam nos Estados Unidos.

Não obstante, para ser coerente com minha proposta, senti a necessidade de alterar o mês do ano em que se inicia o período escolar (de setembro no texto fonte para fevereiro no texto alvo), descrevi ruas e avenidas do centro da cidade de João Pessoa, mencionei nomes de escolas locais com suas respectivas características etc. - essas e outras questões serão mais bem discutidas na seção 2.4, que aprofunda as discussões sobre a tradução.

Faz-se necessário, contudo, refletir mais profundamente sobre alguns outros posicionamentos adotados. Por exemplo, o texto fonte é marcado pelo uso do presente do indicativo como tempo verbal - o que diminui, de certa forma, a distância entre os acontecimentos do passado e o tempo presente. No texto traduzido, por outro lado, optei por utilizar os verbos no pretérito e transformar a narrativa em uma lembrança ainda

\footnotetext{
${ }^{6}$ Últimas décadas do século XX.
} 


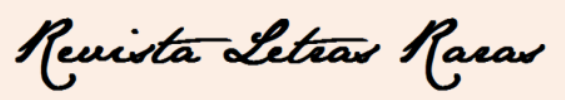

ISSN: 2317-2347 - Vol. 5, Ano 5, № 2 - 2016

mais distante do meu narrador imaginário - manter o tempo presente dos verbos indicaria um relato, mas, ao utilizar o passado, a história passou a ser contada, e esse tom de passado remoto, esse saudosismo, era o que eu desejava marcar na minha tradução.

Em suma, esta seção apresentou o texto fonte, o projeto tradutório e as posturas adotadas na tradução. A seção a seguir busca discutir alguns dos elementos da cultura afro-americana presentes no texto fonte, a relevância desses elementos para a tradução do texto e a forma como o texto traduzido lida com os elementos da cultura alvo para construir a ambientação sociocultural das personagens.

\subsection{Elementos da cultura afro-americana e sua relevância para o texto fonte}

Dentre os elementos do referido texto, merecem destaque a menção feita ao creme para cabelos crespos (Dixie Peach), à revista voltada ao público feminino afroamericano (Ebony), e ao hábito de enrolar os cabelos com dinheiro (dólar) falso para delinear os cachos. $\mathrm{Na}$ tradução, esses elementos não vão ser trabalhados da mesma forma que se apresentam no texto fonte. Eles são mantidos no texto alvo, porém adaptados à cultura de chegada - por exemplo, o dinheiro falso passa a ser o Real e não mais o Dólar, o creme de cabelo passa a ser o reparador de pontas da Jequiti e não o Dixie Peach, e a revista, a Capricho ${ }^{7}$ ao invés da Ebony.

Vale ressaltar que, por se tratar de uma tradução, a proposta a ser aqui problematizada é uma inscrição do texto The First Day com valores e resíduos domésticos, mencionados por Venuti (1995) — dessa forma, a transparência na tradução se torna algo inatingível.

Ainda segundo Venuti (1995), traduzir "significa executar um ato de apropriação, e só em função disso o estrangeiro pode ser apreendido" ${ }^{8}$. Ao me apropriar do texto, escolhi representar algumas particularidades da cultura estrangeira, contemplando-as na tradução segundo um recorte cultural brasileiro. Por exemplo, ao invés de mencionar a revista Ebony como marcador cultural (o que não teria o impacto

\footnotetext{
${ }^{7}$ A revista Capricho não é direcionada para o público afrodescendente brasileiro, e a explicação para sua escolha se encontra na seção 2.4 .

${ }^{8}$ Tradução de: “signifie poser un acte d'appropriation, l'Étranger ne pouvant être appréhendé qu'en fonction du Propre."
} 


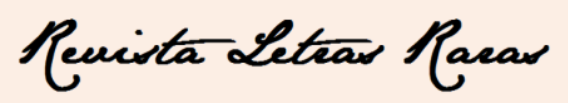

ISSN: 2317-2347 - Vol. 5, Ano 5, № 2 - 2016

desejado sobre o meu leitor), eu incluí o "cuscuz 9 ensopado", um dos registros da cultura africana que, independentemente da origem étnica de cada brasileiro (entendendo-se, aqui, a multirracialidade da sociedade brasileira), fazem parte do seu cotidiano.

Em síntese, esta seção buscou apresentar os elementos de ambientação sociocultural do texto fonte que ressaltam a cultura afro-americana das personagens. Já na próxima seção, são mencionados outros elementos, desta feita, do texto alvo, que merecem consideração por não enfatizarem diretamente essa cultura.

\subsection{Ampliando horizontes}

O texto em português reforça alguns traços afro-americanos das personagens ao contextualizá-los com a cultura de chegada, proporcionando ao leitor a possibilidade de fazer interpretações diferentes da situação retratada por Jones. Dessa forma, a tradução deixa em aberto esse leque de interpretações, mantendo, porém, a coerência textual.

Uma característica que chama a atenção no texto fonte é a referência a algumas personagens a partir de palavras gerais como woman, girl, e my mother. Em apenas duas ocasiões as personagens são referidas pelos nomes próprios, acompanhados do pronome de tratamento Miss. Na tradução, optei por manter o pronome de tratamento, por entender que seria coerente, naquele contexto - em que é mencionado que as senhoritas foram chamadas por um nome desconhecido — , passar uma ideia de que a palavra senhorita estava sendo usada em sentido conotativo - uma vez que é comum, na cultura alvo, o uso de pronomes de tratamento, em situações similares à que ocorre no texto fonte, como sinal de deboche ou provocação.

Um maior distanciamento entre texto fonte e texto alvo foi obtido a partir de alguns alimentos, vestimentas, documentos e determinados objetos escolares mencionados e que foram contextualizados com o estilo de vida paraibano/nordestino. Todas essas escolhas estão afinadas com a proposta de apresentar o nordeste brasileiro e dar visibilidade à tradutora.

\footnotetext{
${ }^{9}$ Prato árabe originário do Magrebe (região do norte de África) feito de milho, e bastante consumido no Brasil, em especial na região nordeste do país.
} 


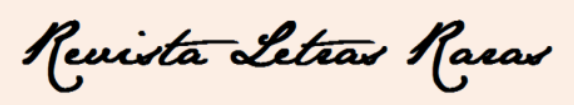

ISSN: 2317-2347 - Vol. 5, Ano 5, № 2 - 2016

Em suma, esta seção expôs alguns pontos que demonstram em quais aspectos os textos — fonte e alvo — se distanciam ou ampliam os horizontes em termos de interpretação.

\subsection{Aprofundamento das discussões}

Nesta seção, são discutidas algumas passagens do texto fonte e suas respectivas traduções para a língua alvo. As passagens aqui apresentadas foram selecionadas em função das escolhas tradutórias que elas apresentam - tendo em vista o propósito deste trabalho de racionalizar sobre o processo tradutório, tentando, assim, estabelecer diálogos em torno da tradução que ultrapassem a dicotomia certo versus errado, mas que se estabeleçam a partir das linhas de raciocínio da tradutora e das reflexões que suas escolhas implicam, seguindo, assim, a proposta de Venuti (1995), mencionada na seção 1 deste trabalho. Trata-se, na maioria dos casos, de marcadores culturais que têm função de ambientar o conto na cultura de partida e das escolhas feitas quando da reflexão sobre o papel desses marcadores na cultura de chegada.

Seguindo a proposta de Meyer (2002) em considerar os contextos temporal, geográfico e sociocultural que constroem a ambientação de narrativas - como discutido na seção 1 deste texto —, esta discussão começa pelos marcadores temporais September e Fevereiro (grifos nossos) ${ }^{10}$ destacados nos exemplos abaixo e discutidos na sequência:

Ex. 1. On an otherwise unremarkable September morning long before I learned to be ashamed of my mother, she takes my hand and we set off down New Jersey Avenue to begin my very first day of school.

Ex. 2. Naquela manhã de fevereiro, igual a tantas outras, e bem antes de eu aprender a sentir vergonha da minha mãe, ela me segurou pela mão e a gente seguiu juntas, passando pela Epitácio Pessoa, a caminho do meu primeiro dia de aula.

Nos trechos apresentados nos Exemplos 1 e 2, estão destacadas (respectivamente) as palavras September e Fevereiro. Embora fevereiro não seja uma das opções mais esperadas quando se fala na tradução da palavra September em

${ }^{10}$ A menos que especificado de outra forma, todas as ocorrências de grifos nos exemplos discutidos nesta seção são nossas. 


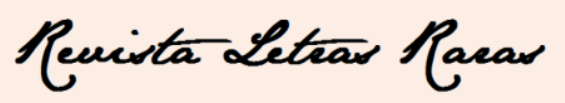

ISSN: 2317-2347 - Vol. 5, Ano 5, № 2 - 2016

situações fora do contexto, no caso da tradução aqui apresentada, existe a compreensão de que o espaço temporal construído no texto fonte destaca o começo de um ano letivo ${ }^{11}$ - o que pode, inclusive, ser visto nos trechos selecionados, quando são feitas referências ao primeiro dia de aula da narradora - e não precisamente o mês de setembro como nono mês do ano. A partir dessa compreensão, foi adotada a tradução do trecho como fevereiro, entendendo que, na cultura alvo, essa referência seria mais facilmente associável ao começo de um ano letivo regular.

Outro elemento de ambientação a ser considerado são as referências a espaços físicos (geográficos). Os exemplos a seguir podem ser usados para discutir essa ambientação:

Ex. 3. We cross New York Avenue, we cross Pierce Street, and we cross $\boldsymbol{L}$ and $\boldsymbol{K}$, and still I see no one who knows my name.

Ex. 4. A gente atravessou a Epitácio, pegou o início da Maximiano Figueiredo, cruzou a Praça da Independência, e nada de ver alguém que eu conhecesse.

Nesses trechos, Exemplos 3 e 4, os vocábulos em destaque, respectivamente, Epitácio, Maximiano Figueiredo e Praça da Independência não são traduções naturalmente adotadas para New York Avenue, Pierce Street, L e K. Os espaços referenciados no conto são relativos à cidade de Washington e ambientam o enredo pretendido nessas ruas do centro da referida cidade. Não obstante, em acordo com a proposta de ambientação do texto de chegada, na cidade de João Pessoa, os espaços geográficos ali destacados referem-se, então, àquelas ruas do centro da cidade paraibana.

Além dos marcadores temporais e das referências a espaços físicos, aparecem também alguns marcadores culturais que são discutidos a partir de agora. Inicialmente, os exemplos 5, 6, 7 e 8 trazem uma construção em torno de cosméticos e perfumaria.

Ex. 5. My nose fills with the faint smell of Dixie Peach hair grease. Ex. 6. Aquele cheirinho do reparador de pontas da Jequiti entrava nariz adentro.

A brilhantina de nome Dixie Peach (Exemplo 5) é utilizada no penteado de cabelos crespos há décadas, em especial na América do Norte, mas também chegou a

\footnotetext{
${ }^{11}$ Em vários países do hemisfério norte, o ano letivo começa nos meses de agosto e setembro.
} 


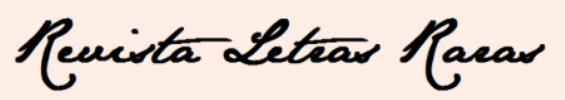

ISSN: 2317-2347 - Vol. 5, Ano 5, № 2 - 2016

ser conhecida nas regiões Sul e Sudeste do Brasil. Os produtos Jequiti (Exemplo 6), no entanto, têm seu nome consagrado como marca de cosméticos essencialmente brasileira, consumida por pessoas de todas as classes socioeconômicas, sendo o seu reparador de pontas o produto escolhido por já fazer parte do cenário cultural brasileiro.

Essa mesma linha de raciocínio é seguida nos dois exemplos seguintes:

Ex. 7. [My mother] has dabbed the stingiest bit of her gardenia perfume.

Ex. 8. [Minha mãe] chiringou um pouco do seu perfume Azzaro.

Mencionado no Exemplo 7, o perfume Azzaro, lançado em diversos países nos anos 1970, é conhecido por misturar essências frescas, aromáticas e amadeiradas. Por esse motivo tem a preferência masculina, mas é também usado pelas mulheres. Sendo este um perfume de preço razoavelmente alto - a que a personagem do conto só teve acesso como último presente do marido antes de abandoná-la - o que, somado ao baixo poder aquisitivo da personagem, justifica a parcimônia com que a personagem o utiliza. Existe, ainda, a compreensão de que o "gardenia perfume" ficaria descontextualizado no cenário paraibano (em comparação com o Azzaro no texto de chegada).

Há, ainda, outros marcadores culturais a serem considerados, como os que fazem referência a hábitos alimentares, como se vê a seguir:

\section{Ex. 9. My stomach is full of milk and oatmeal sweetened with brown sugar. \\ Ex. 10. $\quad \mathrm{Eu}$ tava literalmente empanturrada: inhame, cuscuz ensopado e um pingado.}

Nos Exemplos 9 e 10, estão destacados (respectivamente) milk and oatmeal sweetened with brown sugar e inhame, cuscuz ensopado e um pingado. A despeito de inhame, cuscuz ensopado e um pingado não ser a tradução esperada para milk and oatmeal sweetened with brown sugar, entende-se que, na cultura alvo, essa referência seria mais facilmente relacionada a um desjejum. Foi, desta forma, escolhida como tradução para o trecho equivalente no texto fonte.

Seguem-se outros exemplos de marcadores culturais, desta feita relacionados à política de saúde pública, também discutidos na sequência: 


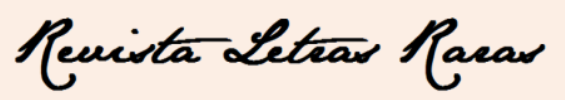

ISSN: 2317-2347 - Vol. 5, Ano 5, № 2 - 2016

Ex. 11. Indeed, she takes out more papers than I have ever seen her do in other places: my birth certificate, my baptismal record, a doctor's letter concerning my bout with chicken pox, rent receipts, records of immunization, a letter about our public assistance payments, even her marriage license.

Ex. 12. Na verdade, ela tirou mais papéis do que eu já vi ela tirar em qualquer outro lugar: minha certidão de nascimento, meu registro de batismo, um atestado médico contando o meu padecimento com a catapora, recibos de aluguel, o cartão de vacinas, o cartão do SUS, até mesmo a certidão de casamento dela.

Nos trechos apresentados nos Exemplos 11 e 12 são mencionados os documentos que comprovam o acesso das personagens à saúde pública americana (no Exemplo 11) e à do Brasil (no Exemplo 12). A escolha do SUS (Sistema Único de Saúde) se deu por ser um serviço acessível a todos os brasileiros, mais notadamente, à população menos favorecida economicamente, a qual frequenta constantemente seus postos de atendimento.

Nos exemplos a seguir, apresenta-se mais um elemento a ser discutido enquanto marcador cultural:

Ex. 13. I am wearing a checkered-like blue-and-green cotton dress, and scattered about these colors are bits of yellow and white and brown.

Ex. 14. [...] eu usava um vestido de chita xadrez, azul e verde, com uns enfeites em amarelo, branco e marrom.

Nos Exemplos 13 e 14, a escolha tradutória para substituir o algodão (presente nessa passagem do texto fonte) foi a chita ${ }^{12}$, tecido bastante conhecido no nordeste brasileiro. Sua inserção no conto reforça e contextualiza a realidade socioeconômica das personagens.

Ainda fazendo uma discussão acerca dos marcadores culturais, os Exemplos 15 e 16 fazem menção a artigos escolares e são ambos mencionados de acordo com cada uma das culturas acessadas nos textos:

Ex. 15. I am carrying a pencil, a pencil sharpener, and a small 10-cent tablet with a black-and-white speckled cover.

Ex. 16. Eu tava levando um lápis, um apontador e um fichário de R\$ 1,99 com a capa enfeitada de lantejoulas pretas e brancas.

\footnotetext{
${ }^{12}$ Definição: "tecido de algodão de pouca qualidade, geralmente estampado a cores". Disponível em: https://www.infopedia.pt/dicionarios/lingua-portuguesa/Chita. Acesso em: 25 ago. 2016.
} 


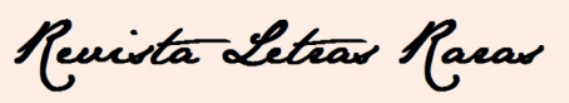

ISSN: 2317-2347 - Vol. 5, Ano 5, № 2 - 2016

Os trechos destacados (10-cent tablet e fichário de $R \$ 1,99)$ se referem a artigos escolares, normalmente utilizados por estudantes. Os artigos — não apenas escolares, mas de uso geral - vendidos em lojas populares que praticavam preços a partir de $\mathrm{R} \$$ 1,99 eram frequentes em todo o Brasil entre o fim da década de 1990 e o começo da década de 2000. Ainda hoje, existem lojas que adotam a prática de trabalhar com preços baixos para atrair parcelas menos favorecidas da população, aquecendo o mercado e se posicionando como uma opção competitiva de comércio. Ao utilizar essa expressão, fica ratificada a condição social das personagens, de forma análoga à construída no texto fonte pela expressão 10 -cent.

Na sequência, são apresentados exemplos relativos à forma como a linguagem das personagens é representada nos contos, destacando-se como marcadores socioculturais - o que pode ser verificado nas análises subsequentes:

\section{Ex. 17. I sense her doubts.}

Ex. 18. Eu senti que ela tava pinando.

No caso dos Exemplos 17 e 18, a tradução buscou, na língua alvo, utilizar um vocábulo reconhecido na cultura de chegada e que tem sentido semelhante ao da língua fonte na cultura de partida. O vocábulo pinando é o gerúndio do verbo pinar, o qual possui várias definições ${ }^{13}$, mas que se trata, também, de um neologismo que, neste caso, tem o sentido de hesitação, hesitando - e é um léxico comumente utilizado por moradores de algumas cidades interioranas nordestinas, principalmente do Estado de Pernambuco, vizinho ao Estado da Paraíba, onde se ambienta a narrativa no texto alvo. Vale salientar que eu vivi toda a minha infância e parte da minha juventude no Estado de Pernambuco, e que, tanto eu quanto as pessoas com quem eu convivia, costumávamos utilizar o referido vocábulo para designar momentos de hesitação ou de medo. Dessa forma, com base em minha experiência pessoal, escolhi o vocábulo pinando, em ratificação à minha decisão de destacar os regionalismos na tradução proposta.

\footnotetext{
${ }^{13}$ Definição em www.dicionarioinformal.com.br/pinando: ficar encostado ou tocando o pênis ereto numa nádega ou coxa de alguém. Acesso em: 25 ago. 2016.

Definição em https://www.infopedia.pt/dicionarios/lingua-portuguesa/pinando: pinar (verbo transitivo) cravar pinos em; (verbo transitivo e intransitivo) vulgarismo ter relações sexuais. Acesso em: 25 ago. 2016.

Definição em: https://www.dicio.com.br/pinando: Significado de Pinar - Meter pinos em; Ter cópula carnal. Acesso em: 25 ago. 2016.
} 


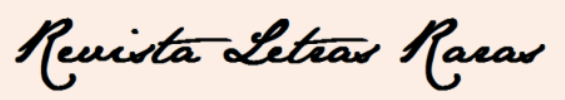

ISSN: 2317-2347 - Vol. 5, Ano 5, № 2 - 2016

Esse mesmo viés linguístico foi utilizado nos exemplos a seguir:

Ex. 19. Strewn about the floor are dozens and dozens of pieces of white paper.

Ex. 20. Tinha um mundaréu de papel espalhado pelo chão.

Para a expressão dozens and dozens, destacada no Exemplo 19, costuma ser dada a tradução dezenas ou dúzias e dúzias, denotando uma grande quantidade. Neste caso, porém, foi escolhido para representar o montante, um vocábulo que manifesta a cultura linguística nordestina (mundaréu) - além do que, esta é uma marca de quantidade mais adequada a uma menina em idade pré-escolar (que, em teoria, ainda não sabe identificar dúzias, dezenas, e afins). O significado de mundaréu ${ }^{14}$ é um grande número de pessoas ou coisas. Esse termo foi utilizado no texto de chegada pelo mesmo motivo do vocábulo pinando (Exemplo 18), ou seja, por fazer parte do léxico utilizado em cidades interioranas nordestinas, contextualizando o conto no ambiente proposto para este trabalho.

A mesma proposta de abordagem linguística foi seguida nos exemplos a seguir:

Ex. 21. My mother is now diseased, according to the girl's eyes.

Ex. 22. A menina tava secando a minha mãe com o olhar.

Neste caso, a escolha tradutória tanto altera a ordem frasal quanto interfere no significado da frase. A inserção do vocábulo secando - o mesmo que azarando — dá ênfase à ação da personagem (a qual fica olhando atentamente para a mãe da narradora), e auxilia na manutenção da coerência lexical do texto traduzido (ratificação da escolha de regionalismos), corroborando o projeto tradutório, mas sem se desviar da mensagem veiculada no texto de partida.

O mesmo acontece nos exemplos seguintes:

Ex. 23. My mother stares.

Ex. 24. Minha mãe ficou ali só cubando.

No Exemplo 24, aparece mais um vocábulo pertencente ao linguajar local cubando $^{15}$, quer dizer olhar atentamente -, que vem a reforçar a proposta de

\footnotetext{
${ }^{14}$ Encontrado em www.priberam.pt/dlpo/mundaréu. Acesso em: 26 ago. 2016.

15 Definição em www.dicionarioinformal.com.br/cubando: Observando, prestando atenção. Usado no nordeste brasileiro. Acesso em: 26 ago. 2016.
} 


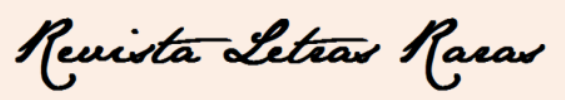

ISSN: 2317-2347 - Vol. 5, Ano 5, № 2 - 2016

representação do cenário nordestino no texto alvo, não sendo a tradução esperada para stares.

Os Exemplos 23 e 24 finalizam a discussão acerca dos marcadores linguísticos aqui analisados. Contudo, alguns outros pontos merecem consideração, a exemplo de marcadores culturais que se referem a elementos da cultura afro-americana.

Observe-se o exposto a seguir:

Ex. 25. Another woman out of the Ebony ads takes the woman's child away.

Ex. 26. Outra mulher que também parecia ter saído da revista Capricho levou embora a filha da mulher.

Os trechos destacados nos Exemplos 25 e 26 suscitam uma interessante discussão acerca da escolha tradutória realizada, e que carece ser discutida. A menção feita à revista Ebony ${ }^{16}$ no conto situa o leitor na ambientação proposta na narrativa. Poderia ter sido escolhida a Revista Raça Brasil ${ }^{17}$, como opção para o texto alvo. Entretanto, seguindo a proposta de Meyer (2002) — já mencionada anteriormente —, em considerar o contexto sociocultural que constrói a ambientação, foi escolhida a Revista Capricho ${ }^{18}$, que, diferentemente da Raça Brasil, circula há mais tempo e é mais conhecida no país. Ademais, a Capricho também veicula conteúdos destinados aos cidadãos afrodescendentes brasileiros, sendo uma opção mais condizente com o público alvo no qual a narradora do conto se encaixa.

São apresentados, a seguir, outros exemplos de marcadores culturais que suscitam discussão:

Ex. 27. The woman who greets us has pearls thick as jumbo marbles that come down almost to her navel.

Ex. 28. A mulher que nos atendeu usava um colar que ia até o umbigo, feito de miçangas tão grossas quanto os dentes do Topo Gigio.

\footnotetext{
16 "Ebony é uma revista mensal norte-americana dedicada ao público afro-descendente, fundada por John Harold Johnson e publicada desde 1945." Retirado de https://pt. wikipedia.org/wiki/Ebony. Acesso em: 25 ago. 2016.

${ }^{17}$ Destinada ao público afro-brasileiro, a Revista Raça Brasil foi lançada em 1996 e passou a ser chamada de Revista Afro Brasil a partir do mês de abril de 2016.

${ }^{18}$ Lançada em 18 de junho de 1952 pelo fundador da Editora Abril, Victor Civita, foi a primeira revista feminina do Brasil e da empresa.
} 


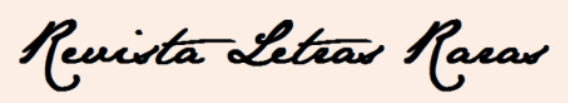

ISSN: 2317-2347 - Vol. 5, Ano 5, № 2 - 2016

Os trechos em destaque nos Exemplos 27 e 28 trazem dois pontos para o debate. Em primeiro lugar, o vocábulo pearls mencionado no texto fonte, devidamente contextualizado na cultura de chegada, se traduzido por pérolas, não estaria de acordo com a proposta aventada no projeto de tradução aqui debatido. Esse vocábulo foi substituído por miçangas no texto alvo — no Brasil, destacadamente na região nordeste, as miçangas são empregadas na confecção de adornos — por se tratar de uma referência cultural mais associável ao contexto brasileiro do que pérolas, levando-se em conta os aspectos sociais que envolvem as personagens.

Em segundo lugar, existe a compreensão de que a personagem Topo Gigio $^{19}$, inserida no texto alvo, constrói um universo mais próximo do leitor na cultura de chegada, uma vez que se trata de uma personagem que se tornou conhecida por várias gerações de brasileiros. Se fosse mantido o vocábulo jumbo (pertencente à cultura norteamericana) a compreensão não teria o efeito desejado, ou seja, não se encaixaria na ambientação pretendida pela tradutora. Escolheu-se manter apenas a noção de se tratar de um animal (elefante no texto fonte e rato no texto alvo).

Outro ponto que merece consideração nos exemplos a seguir é a escolha da tradutora em modificar o efeito que a escola teve sobre a narradora, a partir de um dado descritivo do objeto. Neste ponto em específico, a construção da personagem diverge entre o texto fonte e o texto alvo, como consequência da ambientação. Observe-se:

Ex. 29. Walker-Jones is a larger, new school, and I immediately like it because of that.

Ex. 30. $\quad$ A E. E. E. F. M. Tenente Lucena era uma escola bem simples e eu já gostei dela por causa disso.

No exemplo 29, a larger, new school permite cogitar que existe uma melhora no status da personagem, advinda daí sua felicidade ao constatar que essa seria sua escola. De modo diferente, no texto de chegada, o sentimento de felicidade da personagem reside em ser admitida em uma escola mais simples. A noção de simplicidade permite imaginar uma personagem menos preocupada com o status. Conto e tradução passam mensagens distintas, no entanto, isso não fere os princípios de coerência e informatividade do texto de chegada. Trata-se, tão somente, de um posicionamento da

\footnotetext{
${ }^{19}$ Personagem que representa um ratinho, e que foi criada na Itália em 1958 por Maria Perego.
} 


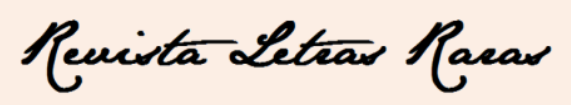

ISSN: 2317-2347 - Vol. 5, Ano 5, № 2 - 2016

tradutora enquanto autora, formatando uma característica da personagem no texto alvo em oposição ao perfil delineado no texto fonte.

Sucede daí uma possível construção diferente (comparando os textos fonte e alvo) da personagem: no texto fonte, ela é desejosa de uma ascensão social, no texto alvo, ela é resignada com sua posição. Esses distintos posicionamentos, refletem cada qual o ambiente cultural de recepção do texto. ${ }^{20}$

Esse mesmo recurso de marcação da presença do tradutor pode ser verificado nos exemplos a seguir:

Ex. 31. I can still hear my mother's footsteps above it all.

Ex. 32. Eu ainda conseguia ouvir os passos da minha mãe no corredor. Toc, toc, toc, toc ...

Os excertos destacados nos Exemplos 31 e 32 retratam a finalização do conto. A opção de incluir uma figura de linguagem, a onomatopeia, para finalizar o texto alvo, visou destacar o efeito da ação descrita na passagem. Esse efeito tenta mostrar que aquela ação ainda reverbera na mente da personagem, mesmo estando distante no tempo - ratificando o saudosismo presente no tempo verbal (mencionado na seção 2.1) escolhido para narrar o conto no texto alvo, e que se desejava destacar - , e, mais uma vez, traz a marca da tradutora.

Nesta seção, foram discutidas algumas passagens do texto fonte, selecionadas em função das escolhas tradutórias, e suas respectivas traduções para a língua alvo. Dessa forma, o propósito deste trabalho, de racionalizar sobre o processo tradutório, foi alcançado, visto que foi proporcionada uma reflexão sobre o local de fala da tradutora em relação ao outro cultural e promovida a visibilidade da tradução.

No intuito de apresentar as demais escolhas tradutórias que não foram contempladas nos exemplos anteriormente analisados, a seção a seguir, apresenta o texto fonte e o texto alvo, lado a lado e na íntegra.

\section{Conto em inglês e respectiva tradução para o português brasileiro}

\begin{tabular}{|l|l|}
\hline The First Day - Edward P. Jones & O Primeiro Dia $-<<$ Tradutora $>>$ \\
\hline
\end{tabular}

${ }^{20} \mathrm{Na}$ seção 4, uma discussão acerca deste aspecto cultural da personagem será novamente retomada. 


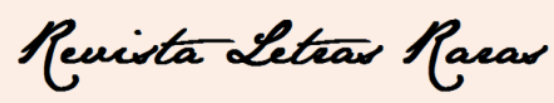

ISSN: 2317-2347 - Vol. 5, Ano 5, № 2 - 2016

On an otherwise unremarkable September morning long before I learned to be ashamed of my mother, she takes my hand and we set off down New Jersey Avenue to begin my very first day of school. I am wearing a checkered-like blue-and-green cotton dress, and scattered about these colors are bits of yellow and white and brown. My mother has uncharacteristically spent nearly an hour on my hair that morning, plaiting and replaiting so that now my scalp tingles. Whenever I turn my head quickly, my nose fills with the faint smell of Dixie Peach hair grease. The smell is somehow a soothing one now and I will reach for it time and time again before the morning ends. All the plaits, each with a blue barrette near the tip and each twisted into an uncommon sturdiness, will last until I go to bed that night, something that has never happened before. My stomach is full of milk and oatmeal sweetened with brown sugar. Like everything else I have on, my pale green slip and underwear are new, the underwear having come three to a plastic package with a little girl on the front who appears to be dancing. Behind my ears, my mother, to stop my whining, has dabbed the stingiest bit of her gardenia perfume, the last present my father gave her before he disappeared into memory. Because I cannot smell it, I have only her word that the perfume is there. I am also wearing yellow socks trimmed with thin lines of black and white around the tops. My shoes are my greatest joy, black patent-leather miracles and when one is nicked at the toe later that morning in class, my heart will break.

I am carrying a pencil, a pencil sharpener, and a small 10-cent tablet with a blackand-white speckled cover. My mother does not believe that a girl in kindergarten needs such things, so I am taking them only because of my insistent whining and because they are presented from our neighbors, Mary Keith and Blondelle Harris. Miss Mary and Miss Blondelle are
Naquela manhã de fevereiro, igual a tantas outras, e bem antes de eu aprender a sentir vergonha da minha mãe, ela me segurou pela mão e a gente seguiu juntas, passando pela Epitácio Pessoa, a caminho do meu primeiro dia de aula - eu usava um vestido de chita xadrez, azul e verde, com uns enfeites em amarelo, branco e marrom. Minha mãe tinha passado quase uma hora ajeitando o meu cabelo - ela fez e refez as tranças até minha cabeça começar a formigar. Se eu tentasse me virar ligeiro, aquele cheirinho do reparador de pontas da Jequiti entrava nariz adentro. Isso até que me deixava mais calminha e passei a manhã inteira cheirando minhas tranças. Com fivelas azuis nas pontas de cada uma, elas foram torcidas com tanta força que iam durar até a hora de eu ir dormir (e isso nunca tinha acontecido). $\mathrm{Eu}$ tava literalmente empanturrada: inhame, cuscuz ensopado e um pingado. Tudo que eu tava usando - a anágua verde claro e a calcinha, por exemplo - era novinho em folha (a calcinha veio em uma embalagem plástica com três peças, estampando a propaganda de uma menina dançando). Atrás das minhas orelhas, minha mãe, na intenção de me fazer parar de reclamar, chiringou um pouco do seu perfume Azzaro, o último presente que meu pai deu a ela antes de sumir. Como eu não conseguia sentir o cheiro da fragrância, eu só tinha a palavra dela de que o perfume estava mesmo lá. Eu tava usando, também, meias amarelas abanhadas com uns bordadinhos em preto e branco. Meus sapatos eram a minha maior alegria, um assombro, de verniz preto - ia partir meu coração se alguém pisasse no meu pé lá na escola.

Eu tava levando um lápis, um apontador e um fichário de $\mathrm{R} \$ 1,99$ com a capa enfeitada de lantejoulas pretas e brancas. Minha mãe não acreditava que uma garotinha no jardim da infância precisasse dessas coisas, então eu só tava com elas por causa da minha insistência e porque foram presentes de nossas vizinhas, Zuleide e Graciete das Neves. Zuleide e 


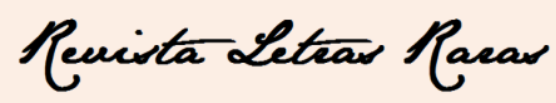

ISSN: 2317-2347 - Vol. 5, Ano 5, № 2 - 2016

watching my two younger sisters until my mother returns. The women are as precious to me as my mother and sisters. Out playing one day, I have overheard an older child, speaking to another child, call Miss Mary and Miss Blondelle a word that is brand new to me. This is my mother. When I say the word in fun to one of my sisters, my mother slaps me across the mouth, and the word is lost for years and years.

All the way down New Jersey Avenue, the sidewalks are teeming with children. In my neighborhood, I have many friends, but I see none of them as my mother and I walk. We cross New York Avenue, we cross Pierce Street, and we cross L and K, and still I see no one who knows my name. At I Street, between New Jersey Avenue and Third Street, we enter Seaton Elementary School, a timeworn, sad-faced building across the street from my mother's church, Mt. Carmel Baptist.

Just inside the front door, women out of advertisements in Ebony are greeting other parents and children. The woman who greets us has pearls thick as jumbo marbles that come down almost to her navel, and she acts as if she had known me all my life, touching my shoulder, cupping her hand under my chin. She is enveloped in a perfume that I only know is not gardenia. When, in answer to her question, my mother tells her that we live at 1227 New Jersey Avenue, the women first seems to be picturing in her head where we live. Then she shakes her head and says that we are at the wrong school, that we should be at Walker-Jones.

My mother shakes her head vigorously, "I want her to go here," my mother says. "If I'da wanted her someplace else, I'da took
Graciete das Neves ficaram cuidando das minhas duas irmãzinhas até minha mãe voltar. Minhas vizinhas eram tão importantes pra mim quanto minha mãe e minhas irmãs. Uma vez, quando eu tava brincando, ouvi uma criança mais velha junto com outra, chamarem a Senhorita Zuleide e a Senhorita Graciete das Neves por um nome que eu não conhecia. Com minha mãe era assim. Ao me ouvir repetir aquela palavra engraçada pra uma das minhas irmãs, minha mãe me deu um tapa na boca e a palavra ficou perdida por anos e anos.

Pela Epitácio Pessoa todinha, se via muitas crianças nas calçadas. No meu bairro, eu tinha muitos amigos, mas não tava vendo nenhum deles durante essa caminhada com minha mãe. A gente atravessou a Epitácio, pegou o início da Maximiano Figueiredo, cruzou a Praça da Independência, e nada de ver alguém que eu conhecesse. Depois de atravessar a Epitácio Pessoa e a Praça da Independência, a gente entrou no Pio X, um prédio com a fachada de arquitetura antiga, sem enfeites, pertinho da igreja da minha mãe, a $1^{\text {a }}$ Igreja Batista de João Pessoa.

No lado de dentro do portão, umas mulheres que pareciam ter saído da revista Capricho, vestidas de preto, cumprimentavam outros pais e filhos. A mulher que nos atendeu usava um colar que ia até o umbigo, feito de miçangas tão grossas quanto os dentes do Topo Gigio. Ela agia como se me conhecesse há muito tempo, colocando a mão no meu ombro e no meu queixo. Ela estava encharcada com um perfume que eu tinha certeza que não era Azzaro. Minha mãe falou pra ela que a gente morava nas Cinco Bocas em Mandacaru e elas fingiram nem saber onde ficava. Depois, a mulher balançou a cabeça e disse que a gente estava na escola errada, que devia ir pra E. E. E. F. M. Tenente Lucena.

Minha mãe se alterou: "Eu quero é que ela fique aqui", afirmou. "Se eu quisesse outra escola, era pra lá que eu ia levá." A 


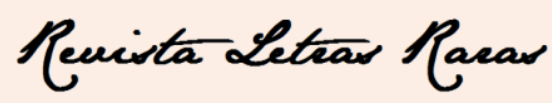

ISSN: 2317-2347 - Vol. 5, Ano 5, № 2 - 2016

her there." The woman continues to act as if she has known me all my life, but she tells my mother that we live beyond the area that Seaton serves. My mother is not convinced and for several more minutes she questions the woman about why I cannot attend Seaton. For as many Sundays as I can remember, perhaps even Sundays when I was in her womb, my mother has pointed across I Street to Seaton as we come and go to Mt. Carmel. "You gonna go there and learn about the whole world." But one of the guardians of that place is saying no, and no again. I am learning this about my mother: The higher up on the scale of respectability a person is - and teachers are rather high up in her eyes - the less she is liable to let them push her around. But finally, I see in her eyes the closing gate, and she takes my hand and we leave the building. On the steps, she stops as people move past us on either side.

"Mama, I can't go to school?" She says nothing at first, then takes my hand again and we are down the steps quickly and nearing New Jersey Avenue before I can blink. This is my mother: She says, "One monkey don't stop no show."

Walker-Jones is a larger, new school, and I immediately like it because of that. But it is not across the street from my mother's church, her rock, one of her connections to God, and I sense her doubts as she absently rubs her thumb over the back of her hand. We find our way to the crowded auditorium where gray metal chairs are set up in the idle of the room. Along the wall to the left are tables and other chairs. Every chair seems occupied by a child or adult. Somewhere in the room a child is crying, a cry that rises above the buzz-talk of so many people. Strewn about the floor are dozens of pieces of white paper, and people are walking over them without any thought of picking them up. And seeing this lack of concern, I am all of a sudden afraid. mulher continuou agindo como se me conhecesse há anos, mas disse pra minha mãe que a gente morava distante dessa escola. Minha mãe não se convenceu e ficou querendo saber por que eu não podia estudar lá. Em todos os domingos de que me lembro, acho que até nos domingos em que eu ainda tava na barriga da minha mãe, ela sempre chamava a atenção pro outro lado da praça quando a gente ia e voltava da Igreja Batista. "É ali que cê vai estudá e sabê tudo sobre o mundo intêro." Mas, um dos seguranças do local ficava repetindo que "não podia". Eu tava aprendendo uma coisa sobre minha mãe: quanto mais respeitável fosse uma pessoa - e, pra minha mãe, os professores eram bastante respeitáveis - menos ela se sentia intimidada. Mas, enfim, eu vi o portão se fechar na sua cara. Ela me pegou pela mão e a gente deixou o prédio. Na calçada, ela parou, porque vinha gente de um lado e de outro.

"Mamãe, eu não posso ir pra escola?" Ela não falou nada, mas depois, pegou na minha mão outra vez e a gente desceu ligeiro pela Epitácio antes que eu conseguisse piscar. Com minha mãe era assim. Foi então que ela falou: "Só não tem remédio pra morte."

A E. E. E. F. M. Tenente Lucena era uma escola bem simples e eu já gostei dela por causa disso. Só não ficava perto da igreja da minha mãe, que era a sua fortaleza, a sua ligação com Deus, e eu senti que ela tava pinando, quando começou a esfregar uma mão na outra. A gente seguiu pro auditório lotado, com umas cadeiras enferrujadas bem no centro. Do lado esquerdo, perto da parede, tinha outras mesas e cadeiras. Pelo que vi, cada cadeira já tava ocupada por uma criança ou um adulto. Em todo canto da sala, dava pra ouvir uma criança chorando, outra gritando e o falatório do povo. Tinha um mundaréu de folhas de papel espalhadas pelo chão e as pessoas andando por cima delas nem pensando em apanhar. Ver aquele desleixo, de repente, me deu medo. 


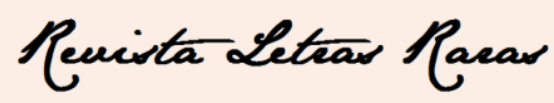

ISSN: 2317-2347 - Vol. 5, Ano 5, № 2 - 2016

"Is this where they register for school?" my mother asks a woman at one of the tables.

The woman looks up slowly as if she heard this question once too often. She nods. She is tiny, almost as small as the girl standing beside her. The woman's hair is set in a mass of curlers, and all of those curlers are made of paper money, here a dollar bill, there a five dollar bill. The girl's hair is arrayed in curls, but some of them are beginning to droop and this makes me happy. On the table beside the woman's pocketbook is a large notebook, worthy of someone in high school, and looking at me looking at the notebook, the girl places her hand possessively on it. In her other hand she holds several pencils with thick crowns of additional erasers.

"These the forms you gotta use?" my mother asks the woman, picking up a few pieces of paper from the table. "Is this what you have to fill out?"

The woman tells her yes, but that she need fill out only one.

"I see," my mother says, looking about the room. Then: "Would you help me with this form? That is, if you don't mind."

The woman asks my mother what she means?

"This form. Would you mind helpin' me fill it out?"

The woman still seems not to understand.

"I can't read it. I don't know how to read or write, and I'm askin' you to help me." My mother looks at me, then looks away. I know almost all of her looks, but this one is brand new to me. Would you help me, then?"

The woman says, "Why sure," and suddenly she appears happier, so much more satisfied with everything. She finishes the form for her daughter, and my mother and I step aside to wait for her.
"É aqui que se faz a inscrição pra escola?" Minha mãe perguntou a uma mulher que tava em uma das mesas.

A mulher levantou a cabeça sem pressa nenhuma, como se tivesse acostumada com a pergunta e, confirmou com a cabeça. Ela era pequena, quase do tamanho da menina que tava do seu lado, tinha o cabelo enrolado em um monte de bobes todos feitos de falsas notas de real uma nota de dois reais aqui, outra nota de cinco ali. O cabelo da menina era cheio de cachos, mas alguns estavam começando a se desmanchar e eu gostei disso. Em cima da mesa, perto da agenda da mulher, tinha um fichário grande, parecido com aquele usado pelos alunos do Ensino Médio e, olhando pra mim e pro caderno, desconfiada, a menina colocou uma das mãos em cima dele. Com a outra mão, ela segurava um bocado de lápis e borrachas grossas.

"São esse os formulário que cê usa?" Minha mãe perguntou à mulher, pegando uns papéis da mesa. "São esse aqui pra preenchê?"

A mulher disse que sim, mas que só precisava preencher um.

"Certo", disse minha mãe, olhando em volta da sala. "Cê pode me ajudá com eles? Qué dizê, se não se importá."

A mulher perguntou à minha mãe o que ela queria dizer com isso.

"Esse formulário. Cê se importa de me ajudá a preenchê?"

Parecia que a mulher ainda não tinha entendido.

"Eu não sei lê. Nem lê, nem escrevê e eu tô pedindo pra você me ajudá." Minha mãe olhou pra mim e, depois, olhou pros lados. Eu conhecia quase todos os seus olhares, mas esse aí era novidade pra mim. "Será que cê pode me ajudá, então?"

A mulher disse: "Com certeza" e, de repente, ela parecia mais contente, muito mais satisfeita com tudo. Ela terminou de preencher o formulário da filha e a gente ficou ali do lado esperando por ela. Tinha 


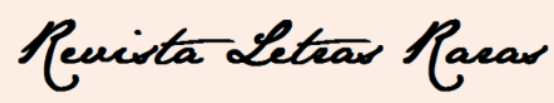

ISSN: 2317-2347 - Vol. 5, Ano 5, № 2 - 2016

We find two chairs nearby and sit. My mother is now diseased, according to the girl's eyes, and until the moment her mother takes her and the form to the front of the auditorium, the girl never stops looking at my mother. I stare back at her. "Don't stare," my mother says to me. "You know better than that."

Another woman out of the Ebony ads takes the woman's child away. Now the woman says upon returning, "Let's see what we can do for you two.”

My mother answers the questions the woman reads off the form. They start with my last name, and then on to the first and middle names. This is school. I think. This is going to school. My mother slowly enunciates each word of my name. This is my mother: As the questions go on, she takes from her pocketbook documents after document, as if they will support my right to attend school, as if she had been saving them up for just this moment. Indeed, she takes out more papers than I have ever seen her do in other places: my birth certificate, my baptismal record, a doctor's letter concerning my bout with chicken pox, rent receipts, records of immunization, a letter about our public assistance payments, even her marriage license - every single paper that has anything even remotely to do with my 5year-old life. Few of the papers are needed here, but it does not matter, and my mother continues to pull out the documents with the purposefulness of a magician pulling out a long string of scarves. She has learned that money is the beginning and end of everything in this world, and when the woman finishes, my mother offers her 50 cents, and the woman accepts it without hesitation. My mother and I are just about the last parent and child in the room.

My mother presents the form to a woman sitting in front of the stage, and the woman looks at it and writes something on a white duas cadeiras vazias e a gente se sentou. A menina tava secando a minha mãe com o olhar e até a mãe dela levar, tanto ela quanto o formulário lá pra frente do auditório, a menina ficou encarando a minha mãe. Eu encarei ela também. "Não é pra ficá encarano," minha mãe me disse, "cê sabe muito bem disso."

Outra mulher que também parecia ter saído da revista Capricho levou embora a filha da mulher. Aí, ela voltou e disse: "Vamos ver o que posso fazer por vocês duas."

Minha mãe respondeu a cada pergunta que a mulher leu no formulário. Começando pelo meu último nome, depois o primeiro e o segundo. A escola era assim. Eu acho. Ir para a escola era assim. Minha mãe falava bem devagar cada palavra do meu nome. Com minha mãe era assim: a cada pergunta que a mulher ia fazendo, ela ia tirando da pasta, documento atrás de documento, como se eles fossem garantir o meu direito de frequentar a escola, como se ela tivesse guardado todos eles só pra esse momento. $\mathrm{Na}$ verdade, ela tirou mais papéis do que eu já vi ela tirar em qualquer outro lugar: minha certidão de nascimento, meu registro de batismo, um atestado médico contando o meu padecimento com a catapora, recibos de aluguel, o cartão de vacinas, o cartão do SUS, até mesmo a certidão de casamento dela - qualquer papel que mesmo de longe pudesse ter alguma coisa a ver com a minha curta vida de 5 anos de idade. Poucos desses papéis foram necessários, mas não importava e minha mãe continuava a puxar os documentos como um mágico que puxa um lenço atrás do outro. Ela tinha aprendido que o dinheiro era a mola do mundo, e assim que a mulher acabou, minha mãe ofereceu seus 5 reais e a mulher aceitou na hora. Só sobrou a gente na sala.

Minha mãe entregou o formulário a uma mulher sentada lá na frente. Ela olhou o papel e escreveu algo em um cartão branco 


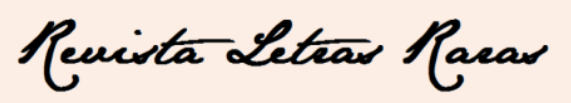

ISSN: 2317-2347 - Vol. 5, Ano 5, № 2 - 2016

card, which she gives to my mother. Before long, the woman who has taken the girl with the drooping curls appears from behind us, speaks to the sitting woman, and introduces herself to my mother and me. She's to be my teacher, she tells my mother. My mother stares.

We go into the hall, where my mother kneels down to me. Her lips are quivering. "I'll be back to pick you up at 12 o'clock. I don't want you to go nowhere. You just wait right here. And listen to every word she say." I touch her lips and press them together. It is an old, old game between us. She puts my hand down at my side, which is not part of the game. She stands and looks a second at the teacher, then she turns and walks away. I see where she has darned one of her socks the night before. Her shoes make loud sounds in the hall. She passes through the doors and I can still hear the loud sounds of her shoes. And even when the teacher turns me toward the classrooms and I hear what must be the singing and talking of all the children in the world, I can still hear my mother's footsteps above it all. e entregou à minha mãe. Em pouco tempo, a mulher que levou a menina com os cachos caídos apareceu atrás da gente, falou com a mulher sentada, que apresentou minha mãe e eu. Ela disse que aquela ía ser a minha professora. Minha mãe ficou ali só cubando.

A gente foi pra recepção e lá minha mãe se ajoelhou na minha frente. Os seus lábios tremiam. "Eu venho te buscá de meio-dia. Eu não quero que cê vá a lugá nenhum. É só esperá aqui. E obedecê o que ela dissé." Eu encostei a mão na boca da minha mãe e apertei de leve - era uma brincadeira bem antiga entre a gente. Ela colocou minhas mãos alinhadas na lateral do meu corpo - isso não fazia parte da brincadeira. Aí então, se levantou e olhou um instante para a professora, depois, se virou e foi embora. Dava pra ver o remendo na meia-calça, feito na noite passada. Seus sapatos faziam barulho no corredor. Ela passava pelas portas e eu ainda podia ouvir o barulho dos sapatos. E mesmo quando a professora me levou para a sala de aula - onde eu pude ouvir o que devia ser a cantoria e o falatório de todas as crianças do mundo - eu ainda conseguia ouvir os passos da minha mãe no corredor. Toc, toc, toc, toc ...

\section{Considerações da tradutora}

O material apresentado neste artigo, que objetivou apresentar uma tradução comentada do conto em inglês The First Day, do escritor Edward P. Jones, para o português brasileiro contemporâneo, possibilitou inúmeras reflexões sobre a importância do cenário para a construção de uma história.

O projeto tradutório teve o desafio de ambientar o conto no cenário nordestino brasileiro, mais especificamente, no cenário paraibano, o que, como discutido ao longo deste artigo, implica mudanças na interpretação do enredo - como mostra a análise empreendida na seção 2.4. Entende-se que, os efeitos na comunidade receptora do texto 


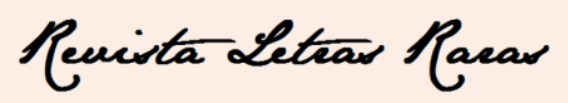

ISSN: 2317-2347 - Vol. 5, Ano 5, № 2 - 2016

de chegada podem até ser distintos dos que ocorrem na comunidade receptora do texto de partida.

A reflexão sobre elementos da cultura afro-americana e papéis sociais puderam ser suscitadas a partir de ambos os textos, cada qual sendo coerente com a informação que se propôs veicular. Para contextualizar, cito os Exemplos 29 e 30, discutidos na seção anterior, em que a noção de simplicidade permite imaginar uma personagem menos preocupada com seu status, sendo essa interpretação plausível no contexto e sem ferir os princípios de coerência e informatividade do texto de chegada.

Este artigo traz um convite à reflexão, a se pensar e repensar principalmente o papel do/a tradutor/a enquanto autor/a e agente social. Mesmo estando inserido/a em uma cultura periférica, ao se apropriar de um texto de uma cultura central, o/a tradutor/a detém um poder de ação, podendo contribuir ao informar, dar voz e consciência política aos que são tratados como desiguais. Contudo, outros convites subjazem essa reflexão, inclusive em relação ao racismo, à discriminação e ao preconceito na cultura do texto de chegada.

Sem a pretensão de encerrar o debate sobre as escolhas tradutórias realizadas e entendendo que não existe uma única tradução para cada texto, sinto-me profundamente gratificada pelo resultado da tarefa realizada, mas, principalmente, pela oportunidade de debater as questões aqui postas - concernentes a cenário, elementos da cultura afroamericana, visibilidade da tradutora, grupos marginalizados - contribuindo com minha tradução para diminuir as desigualdades e modificar a marginalidade cultural. Esses são pontos positivos que aponto do processo e do projeto tradutórios e que podem responder a questões como: Traduzir por quê? Para quem? Como? Poderia acrescentar ainda Traduzir onde?, pois revisitando Venuti (1995), meu local de fala enquanto tradutora me permite sair da invisibilidade no momento em que cristalizo no meu texto os aspectos da minha realidade cultural, argumentando com ela e diversificando as interpretações textuais.

Abrindo um questionamento sobre racismo no Brasil — país que vem ignorando a desigualdade entre as raças, como se percebe ao longo de sua História, mas que dá sinais de mudanças - vale declarar que se trata de um movimento flexível e sutil, situando-se aí sua maior força. Dessa forma, se torna mais difícil identificar seus 


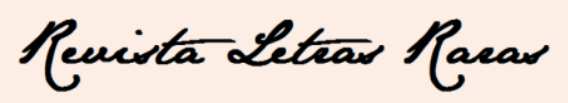

ISSN: 2317-2347 - Vol. 5, Ano 5, № 2 - 2016

matizes e combater as injustiças que atingem os cidadãos afro-brasileiros, algumas das quais levemente discutidas a partir da tradução do conto The First Day. Cabe trazer aqui a representação da narradora do conto no texto alvo, discutida na seção 2.4, Exemplo 30. A personagem tem um posicionamento de resignação quanto ao seu lugar social e fica feliz por ir estudar em uma escola mais simples. Esse perfil foi assim definido com a intenção clara de problematizar a autoestima de um cidadão afrodescendente brasileiro, que interioriza os preconceitos e a discriminação e acaba por se anular enquanto ator social.

Em suma, muitos outros convites, além do questionamento das relações raciais no Brasil, podem ser postos a partir deste trabalho, mas acredita-se que eles emergirão em cada leitor e podem suscitar a escrita de outros projetos que se firmarão como iniciativas de extrema importância para enriquecer o fazer tradutório que aborde a temática afro.

\section{Referências}

BAKER, M. The Changing Landscape of Translation and Interpreting Studies. In: BERMANN, S.; PORTER, C. A Companion to Translation Studies. Oxford: John Wiley \& Sons, Ltd., 2014. p. 15-27.

BERMAN, A. Pour une critique des traductions: John Donne. Paris: Gallimard, 1995.

JONES, E. P. The first day. In: JONES, E. P. Lost in the City. New York: HarperCollins Publishers, 2004.

MEYER, M. The Compact Bedford Introduction to Literature: Reading, Thinking, Writing. Boston: Bedford/St. Martin's, 2002.

VENUTI, L. Escândalos da tradução. Tradução de Laureano Pelegrin, Lucinéia Villela, Marileide Esqueda, Valéria Biondo, Bauru: EDUSC, 1995. 396p.

The Translator's Invisibility: A History of Translation. London/New York: Routledge, 1995.

Recebido em: 15/09/2016

Aceito em: 30/09/2016 